\title{
L-Deprenyl Reverses Age-Associated Decline in Splenic Norepinephrine, Interleukin-2 and Interferon- $\gamma$ Production in Old Female F344 Rats
}

\author{
Srinivasan ThyagaRajan ${ }^{\mathrm{a}}$ Kelley S. Madden ${ }^{\mathrm{b}}$ Gary W. Boehm ${ }^{\mathrm{c}}$ \\ Suzanne Y. Stevens ${ }^{b}$ David L. Felten ${ }^{d}$ Denise L. Bellinger ${ }^{a}$ \\ ${ }^{a}$ Department of Pathology and Human Anatomy, Loma Linda University School of Medicine, Loma Linda, Calif., \\ ${ }^{b}$ Department of Neurobiology and Anatomy, University of Rochester School of Medicine, Rochester, N.Y., \\ 'Department of Psychology, Texas Christian University, Fort Worth, Tex., and ${ }^{\mathrm{d}}$ Oakland University William \\ Beaumont School of Medicine, Royal Oak, Mich., USA
}

\section{Key Words}

Aging $\cdot D$-(+)-Deprenyl $\cdot$ Immunosenescence $\cdot$ Sympathetic activity $\cdot$ T lymphocytes

\begin{abstract}
Aging in female rats is associated with cessation of reproductive cycles, development of mammary cancer, and increased incidence of autoimmune diseases. Previously, we demonstrated an age-related decline in sympathetic noradrenergic (NA) innervation in the spleen and lymph nodes of female F344 rats accompanied by significantly reduced natural killer cell activity, interleukin (IL)-2 and interferon (IFN)- $\gamma$ production, and T- and B-cell proliferation, suggesting possible links between sympathetic activity and immunosenescence. Objectives: The aim of this study is to investigate the effects of $\mathrm{L}-(-)$-deprenyl, a monoamine oxidase-B inhibitor, on the sympathetic nervous system and cell-mediated immune responses in old female rats. Methods: Low doses of L-deprenyl ( 0.25 or $1.0 \mathrm{mg} / \mathrm{kg}$ body weight, BW) were administered intraperitoneally to 19- to 21-month-old female F344 rats for 8 weeks. To assess the stereoselectivity of the effects of deprenyl on splenic sympathetic activity and immune responses, the D-enantiomer (D-(+)-deprenyl; $1.0 \mathrm{mg} / \mathrm{kg} \mathrm{BW}$ )
\end{abstract}

was also included in the studies. Norepinephrine (NE) concentration and content, and mitogen-induced T-cell proliferation and cytokine production were assessed in the splenocytes after deprenyl treatment. Results: Treatment with L-deprenyl reversed the age-related decrease in NE concentration and content and IFN- $\gamma$ production, and increased IL-2 production in the spleen while D-deprenyl did not affect the age-associated reduction in splenic NE levels or cytokine production. Conclusions: These findings demonstrate that L-deprenyl exerts neurorestorative and immunostimulatory effects on the sympathetic nervous system and cell-mediated immune responses during aging and provides evidence for a causal relationship between some aspects of immunosenescence and the age-related decline in sympathetic nerves in the spleens of female F344 rats.

Copyright $\odot 2012$ S. Karger AG, Basel

\section{Introduction}

The sympathetic noradrenergic (NA) neuronal system in the lymphoid organs is a key regulator of immunity, and impairment in its functions with advancing age is responsible for the development of age-associated neuro-

\section{KARGER \\ Fax +41613061234 \\ E-Mail karger@karger.ch}

www.karger.com (c) 2012 S. Karger AG, Basel

1021-7401/13/0202-0072\$38.00/0

Accessible online at:

www.karger.com/nim
Srinivasan ThyagaRajan

Integrative Medicine Laboratory, Department of Biotechnology

School of Bioengineering, SRM University

Kattankulathur 603203 (India)

E-Mail thyagarajan.s@ktr.srmuniv.ac.in 
degenerative disorders, infectious and autoimmune diseases, and cancer [reviewed in ref. 1-3]. Several studies from our laboratory have established the presence of sympathetic NA nerve fibers, its modulation of immunity by norepinephrine (NE) through predominantly $\beta_{2^{-}}$ adrenergic receptors on the $\mathrm{T}$ and $\mathrm{B}$ lymphocytes, and the age-associated decline in NA neuronal density and NE levels paralleling immunosuppression in the spleen of male F344 rats [3-5]. Several experimental approaches have been employed to intervene with immunosuppression, cognitive decline, and development of diseases and cancer during aging, including calorie restriction [6], supplementation with natural antioxidants, vitamin E, and polyunsaturated fatty acids $[7,8]$, hormones, cytokines and growth factors [9]. We have previously reported that L-deprenyl, a monoamine oxidase-B inhibitor, is capable of restoring sympathetic NA nerve fibers and NE levels in the spleens of young 6-hydroxydopamine-treated, old male, and tumor-bearing female rats [2, 10-13]. The neurorestorative properties of deprenyl in the spleen were associated with enhanced natural killer (NK) cell activity, cytokine production, and suppression of tumor growth in tumor-bearing rats.

L-Deprenyl was initially developed as a monoamine oxidase-B inhibitor for the treatment of Parkinson's disease but later found to be useful in the treatment of Alzheimer's disease and extension of life-span in rats. These effects may be mediated through the enhancement of antioxidant enzyme activity, neuroprotective properties by protecting the neurons from chemical and mechanical insults, and augmentation of growth factor biosynthesis [14-16]. Recently, we have provided evidence for an ageassociated reduction in sympathetic NA innervation and NE levels in the spleen of female F344 rats that was accompanied by significant reductions in NK cell activity, interleukin-2 (IL-2) and interferon- $\gamma$ (IFN- $\gamma$ ) production, and T and B cell proliferation [17]. The present study was conducted to examine whether deprenyl treatment of old female rats would reverse the age-associated reductions in splenic NE levels and cell-mediated immune responses measured by IL- 2 and IFN- $\gamma$ production and Tlymphocyte proliferation.

\section{Materials and Methods}

\section{Animals}

Female 3-month-old and 19- to 21-month-old F344 rats (from Charles River Laboratories, obtained through Roche Bioscience, Palo Alto, Calif., USA) were housed 2 per cage in a lightcontrolled (12-hour light:12-hour dark cycle) animal room and were provided food and water ad libitum. The 3-month-old female rats $(n=9)$ were used as young baseline controls. The old female F344 rats ( $\mathrm{n}=10-11$ /group) were administered 0.25 or 1.0 $\mathrm{mg}$ i.p. L-(-)-deprenyl/kg body weight (BW)/day. Another group of female rats $(\mathrm{n}=10)$ were treated with $1.0 \mathrm{mg}$ i.p. $\mathrm{D}$ - $(+)$-deprenyl/kg BW to examine the stereoselectivity of neural-immune effects of deprenyl. A separate group $(n=10)$ of old female rats were treated intraperitoneally with physiological saline that was used as the vehicle for L-(-) and D-(+)-deprenyl. The lower doses were chosen based on studies published from our laboratory [10, $11,13]$. The duration of the treatment period was 8 weeks. At the end of the treatment period, animals were decapitated, and spleens were removed aseptically and used for immunological assays, including concanavalin A (ConA)-induced proliferation and IL- 2 and IFN- $\gamma$ production. A separate small block of the spleen from the hilar region was frozen on dry ice and stored at $-80^{\circ} \mathrm{C}$ until neurochemical analysis of NE by high-performance liquid chromatography with electrochemical detection (HPLCEC). All animal experiments were conducted in accordance with the principles and procedures outlined in the National Institutes of Health (NIH) Guide for the Care and Use of Laboratory Animals, and were approved by the institutional animal care and use committee.

\section{Lymphocyte Preparation}

A block of the spleen was placed in Hanks' balanced salt solution (HBSS; Sigma-Aldrich, St. Louis, Mo., USA) containing sodium bicarbonate and HEPES (United States Biochemical Corp., Cleveland, Ohio, USA). The tissues were then dissociated using a Stomacher Lab-Blender (Tekmar Co., Cincinnati, Ohio, USA). Cell suspensions were passed through fine nylon mesh to remove large aggregates and washed one time in HBSS. Erythrocytes were removed by layering the cell suspension on Histopaque 1077 (Sigma-Aldrich) and centrifuging for $30 \mathrm{~min}$ at 2,500 rpm. Cells were removed from the interface between the HBSS and the Histopaque, and washed three times in HBSS. After the final wash, cells were resuspended to the desired concentration in RPMI 1640 medium supplemented with $5 \%$ fetal calf serum (Sigma-Aldrich), $1 \mathrm{~mm}$ sodium pyruvate, $2 \mathrm{mM}$ L-glutamine, $0.01 \mathrm{mM}$ nonessential amino acids, $5 \times 10^{-5} \mathrm{M} 2$-mercaptoethanol, $100 \mathrm{U} / \mathrm{ml}$ penicillin, $100 \mathrm{mg} / \mathrm{ml}$ streptomycin, $24 \mathrm{~mm}$ sodium bicarbonate, and $10 \mathrm{~mm}$ HEPES for in vitro culture.

Lymphocytes $\left(2 \times 10^{5}\right.$ cells/well $)$ were incubated in triplicate with either medium alone or $1.25 \mu \mathrm{g} / \mathrm{ml}$ of ConA in 96-well, flatbottom tissue culture plates (Falcon, Becton Dickinson, Oxnard, Calif., USA). After $24 \mathrm{~h}$ of culture, $100 \mu \mathrm{l}$ of supernatant were removed from each well and stored in 96-well flat-bottom tissue culture plates at $-20^{\circ} \mathrm{C}$ until assay.

\section{Assay for IL-2 Production}

Supernatants collected from the above experiment were tested for the ability to support the growth of the IL-2-dependent cell line, CTLL-2. Supernatants from individual wells were serially diluted and incubated with $4 \times 10^{3}$ CTLL- 2 cells in a total volume of $100 \mu \mathrm{l}$ for $40 \mathrm{~h}$. Cell growth was then determined using a colorimetric assay as described previously [11]. Ten microliters of 5.0 $\mathrm{mg} / \mathrm{ml}$ 3-(4,5-dimethyl-thiazol-2-yl-)2,5-diphenyltetrazolium bromide (Sigma) in HBSS were added to each well. After incubating for $4 \mathrm{~h}$ at $37^{\circ} \mathrm{C}, 100 \mu \mathrm{l}$ of $0.04 \mathrm{~N} \mathrm{HCl}$ in isopropanol were added to dissolve the colored precipitate. Absorbance was measured 
Fig. 1. NE concentration (a) and total NE content (b) in the spleen of female F344 rats treated with L-(-)- and D-(+)-deprenyl (Dep.) for 8 weeks. NE concentration (a) in the hilar region of the spleen significantly $(\mathrm{p}<0.005)$ declined in old compared with young female rats while it increased in old rats that received both doses of $\mathrm{L}$-deprenyl. Treatment with D-deprenyl had no effect on splenic NE concentration. There was an age-related decline in NE content (b) in the spleen of old female rats $(\mathrm{p}<0.001)$ while it was higher in rats that received $1.0 \mathrm{mg} /$ $\mathrm{kg}$ BW L-deprenyl alone compared to saline-treated old female rats. ${ }^{*} \mathrm{p}<0.005$ vs. young; ${ }^{* *} \mathrm{p}<0.001$ vs. old female rats treated with saline.

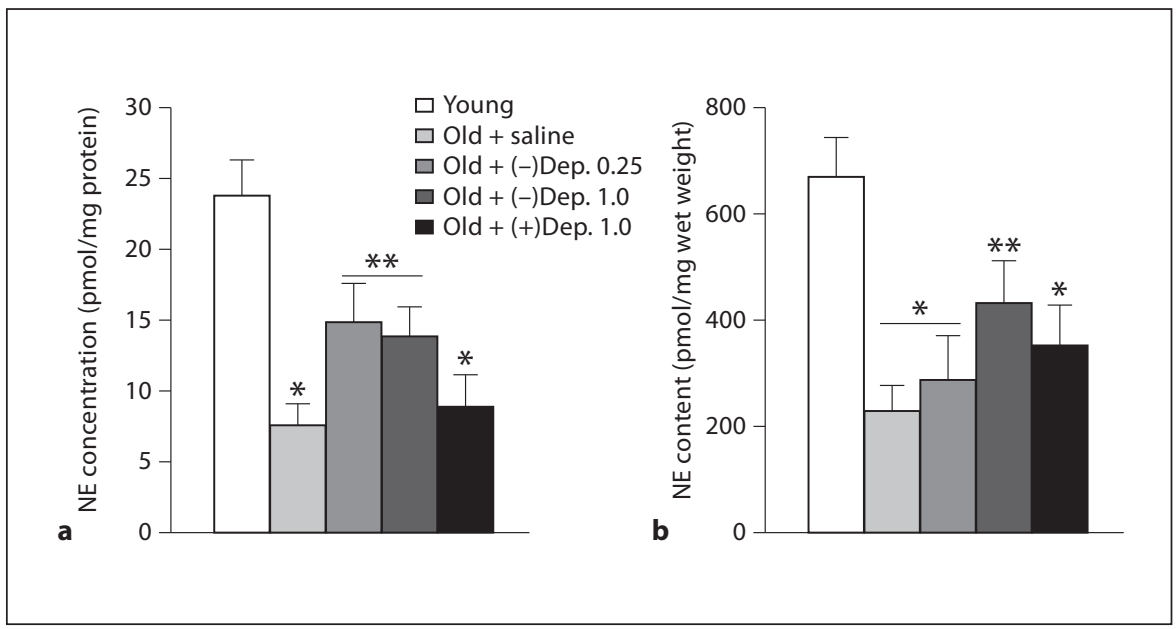

with a microplate reader (Bio-Tek Instruments, Winooski, Vt., USA) using a test wavelength of $570 \mathrm{~nm}$ and a reference wavelength of $630 \mathrm{~nm}$. Background values (CTLL-2 cells incubated with medium only) were subtracted automatically from each value. These values were compared to recombinant murine IL-2 (Genzyme, Cambridge, Mass., USA).

\section{Assay for IFN- $\gamma$ Production}

IFN- $\gamma$ levels in supernatants were determined by ELISA. ELISA plates (Corning, Corning, N.Y., USA) were coated overnight at $4{ }^{\circ} \mathrm{C}$ with purified anti-rat IFN- $\gamma$ polyclonal antibody ( $1 \mu \mathrm{g} / \mathrm{ml}$; Biosource International, Camarillo, Calif., USA) in $0.1 \mathrm{M} \mathrm{Na}_{2} \mathrm{HPO}_{4}$ buffer ( $\mathrm{pH}$ 9.0). In between steps, plates were washed with phosphate-buffered saline (PBS; pH 7.4) containing 0.05\% Tween-20 (PBS/Tween). Plates were then blocked for $2 \mathrm{~h}$ with PBS-10\% fetal equine serum (FES) at room temperature. Recombinant rat IFN- $\gamma$ (Biosource International) or samples serially diluted in culture media were added to plates in triplicate and incubated overnight at $4^{\circ} \mathrm{C}$. Biotin-conjugated anti-rat IFN- $\gamma(0.5$ $\mu \mathrm{g} / \mathrm{ml}$ ) diluted in PBS-10\% FES was added to each well, and the plates were incubated at room temperature for $1 \mathrm{~h}$. Avidin-peroxidase (Sigma), diluted 1:400 in PBS-10\% FES, was added to the plates and incubated for $30 \mathrm{~min}$ at room temperature. In the final step, substrate ABTS [2,2'-azino-bis(3-ethylbenzthiazoline-6sulfonic acid); Sigma] containing $0.03 \%$ hydrogen peroxide was added to the plates and incubated for $30 \mathrm{~min}$ at room temperature. Absorbance at $405 \mathrm{~nm}$ was measured with a microplate reader (Bio-Tek Instruments) after $30 \mathrm{~min}$. The rat IFN- $\gamma$ production by ELISA had a sensitivity of $10 \mathrm{pg} / \mathrm{ml}$.

\section{ConA-Induced Proliferation}

Spleen cells, $2 \times 10^{5}$ cells/well, were cultured in triplicate with either medium alone or varying concentrations of ConA (Calibiochem-Behring Corp., La Jolla, Calif., USA) in 96-well, flat-bottom tissue culture plates (Falcon) and maintained for 3 days at $37^{\circ} \mathrm{C}$ in a humidified $5 \% \mathrm{CO}_{2}$ incubator. $\left[{ }^{3} \mathrm{H}\right]$-thymidine $(0.5 \mu \mathrm{Ci} / 10 \mu \mathrm{l}$; $5 \mathrm{Ci} / \mathrm{mmol}$; DuPont NEN, Boston, Mass., USA) was added for the final $18 \mathrm{~h}$ of culture. Cells were harvested onto glass fiber filter paper (Whatman Inc., Clifton, N.J., USA) with a cell harvester (Skatron, Lier, Norway). The dried filters were placed in scintilla- tion fluid (Biosafe II; RPI, Mount Prospect, Ill., USA), and radioactivity was determined with a liquid scintillation counter (LKB, Wallac, Finland).

\section{HPLC-EC}

Prior to analysis by HPLC-EC, NE in the spleen was extracted with alumina. Tissues were homogenized in $0.1 \mathrm{M}$ of $\mathrm{HClO}_{4}$ with $0.25 \mu \mathrm{m}$ of 3,4-dihydroxybenzylamine as the internal standard and were centrifuged at $1,000 \mathrm{~g}$ for $5 \mathrm{~min}$. The supernatants were used for the aluminum oxide extraction while the pellets were saved for the protein assay (Bio-Rad assay kit). At the time of HPLC-EC analysis, the alumina-extracted samples were loaded onto a Waters 717plus autosampler (Waters, Milford, Mass., USA), and NE concentration was measured using HPLC-EC as described previously $[10,11]$. The NE concentrations and NE content in the spleens were expressed in terms of both picomoles per milligram protein and picomoles per milligram wet weight of spleen, respectively.

\section{Statistical Analysis}

The data were analyzed by one-way analysis of variance (ANOVA). Parameters that attained significance following ANOVA $(p<0.05)$ were further analyzed by Fisher's least significant difference test.

\section{Results}

Old female rats irrespective of the treatment regimen showed an age-related decline in the concentration of $\mathrm{NE}$ in the hilar region of the spleen compared to young rats (fig. 1a). Treatment of old female rats with both doses of L-deprenyl significantly ( $p<0.005)$ increased NE concentration while D-deprenyl had no effect on the agerelated decrease in splenic NE concentration. There was a similar age-related reduction in NE content in the whole spleen of old female rats regardless of the treat- 


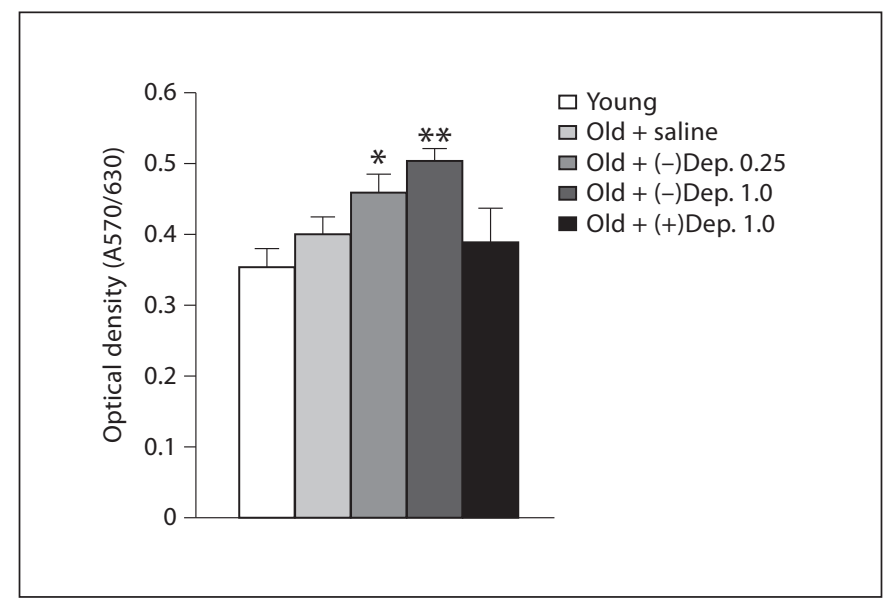

Fig. 2. IL-2 production by spleen cells from old female F344 rats treated with L-(-)- and D-(+)-deprenyl (Dep.) for 8 weeks. Spleen cells were incubated with $1.25 \mu \mathrm{g} / \mathrm{ml}$ of ConA for $24 \mathrm{~h}$. Supernatants were cultured with the IL-2-dependent cell line CTLL, and cell growth was measured colorimetrically. ${ }^{*} \mathrm{p}<0.05$ vs. young; ${ }^{* *} \mathrm{p}<0.05$ vs. young, old + saline, and old $+(+)$ Dep. 1.0 groups.

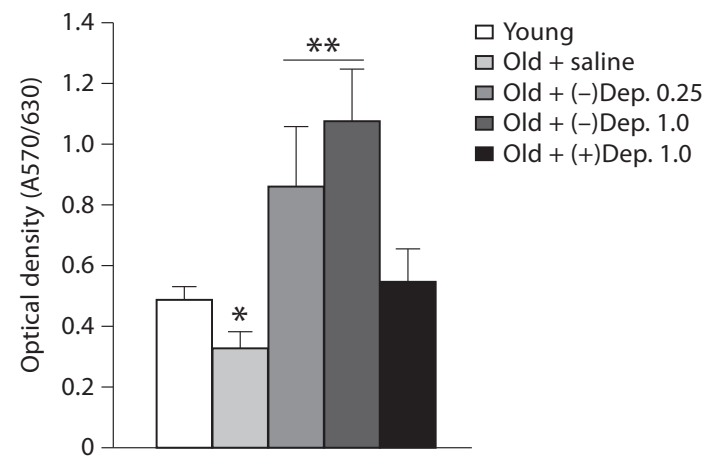

Fig. 3. IFN- $\gamma$ production (by spleen cells from old female F344 rats treated with L-(-)- and D-(+)-deprenyl (Dep.) for 8 weeks. Spleen cells were incubated with $1.25 \mu \mathrm{g} / \mathrm{ml}$ of ConA for $24 \mathrm{~h}$. Supernatants were used to measure IFN- $\gamma$ production by ELISA. ${ }^{*} \mathrm{p}<0.005$ vs. young; ${ }^{* *} \mathrm{p}<0.005$ vs. young, old + saline, and old $+(+)$ Dep. 1.0 groups.
Fig. 4. ConA-induced T-lymphocyte proliferation by spleen cells from old female F344 rats treated with L-(-)- and D-(+)deprenyl (Dep.) for 8 weeks. Spleen cells were incubated with $0,0.3,1.25$, or $5 \mu \mathrm{g} /$ $\mathrm{ml}$ of ConA for $72 \mathrm{~h}$. Proliferation of $\mathrm{T}$ lymphocytes was significantly $(p<0.05)$ reduced in old female rats irrespective of the treatment, but it was more marked in rats that received $1.0 \mathrm{mg} / \mathrm{kg}$ BW D-deprenyl. ${ }^{*} \mathrm{p}<0.005$ vs. young; ${ }^{* *} \mathrm{p}<0.005$ vs. the other four groups.

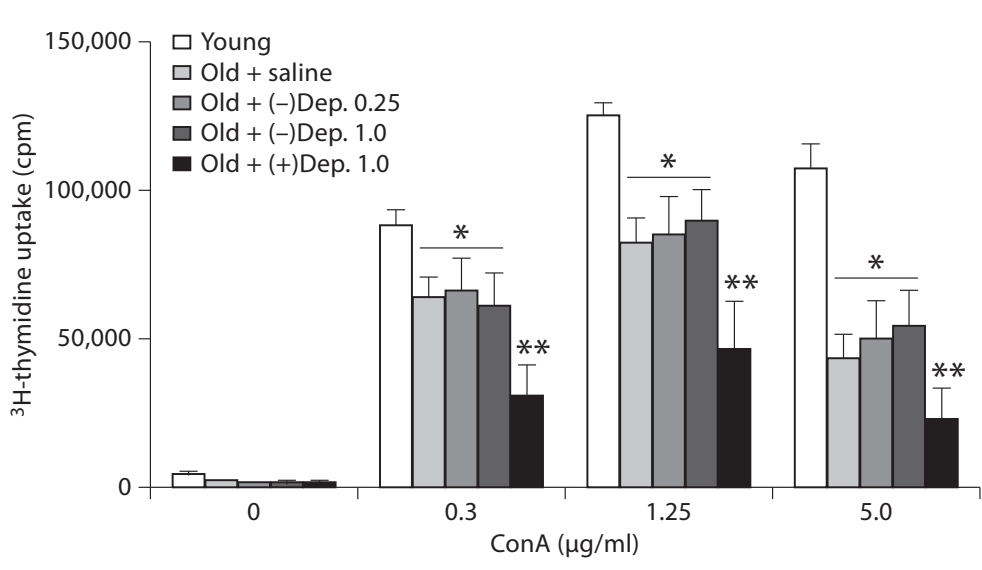

$\mathrm{kg}$ BW of L-deprenyl also increased ConA-induced IL-2 production compared to young and old rats treated with saline and $1.0 \mathrm{mg} / \mathrm{kg} \mathrm{BW}$ of D-deprenyl.

In contrast to IL-2 production by splenocytes, quantification of IFN- $\gamma$ production demonstrated an age-related decrease $(\mathrm{p}<0.005)$ in saline-treated old female rats (fig. 3). This age-related decline in IFN- $\gamma$ production by splenocytes was reversed by treatment with 0.25 and 1.0 $\mathrm{mg} / \mathrm{kg}$ BW of L-deprenyl. Treatment with D-deprenyl 
prevented the age-related decline in IFN- $\gamma$ production without significantly enhancing its level.

Similar to splenic NE levels, there was a marked ( $\mathrm{p}<$ $0.05)$ decrease in the ConA-induced proliferative capacity of $\mathrm{T}$ lymphocytes in old female rats (fig. 4). Chronic treatment of old female rats with either dose of L-deprenyl for 8 weeks did not alter the age-related decline in ConAinduced proliferation of $\mathrm{T}$ cells. In contrast, treatment of old female rats with $1.0 \mathrm{mg} / \mathrm{kg}$ BW of D-deprenyl further reduced the proliferation of $\mathrm{T}$ lymphocytes.

\section{Discussion}

In the present study, we demonstrated that L-deprenyl exerted specific partial reversal of the age-associated decline in splenic NE levels and Th1 cytokine production (IL- 2 and IFN- $\gamma$ production) by mitogen-activated splenocytes from old female F344 rats. In contrast, D-deprenyl had no effect on splenic sympathetic NA neuronal activity and immune responses. These findings are consistent with our earlier published studies on the neurorestorative and immunostimulatory properties of deprenyl in the spleens from old male F344 rats [10-13].

Recently, we have reported that sympathetic NA innervations and NE levels were reduced in the secondary lymphoid organs (spleen and mesenteric lymph nodes) and accompanied by significant reductions in NK cell activity, IL- 2 and IFN- $\gamma$ production, and T- and B-cell proliferation of splenocytes of old female F344 rats, suggesting that the lack of NA innervation and reduction in NE levels may be one of the leading causes of age-associated immunosuppression in old female rodents [17]. The increase in splenic NE concentration in the hilar region and $\mathrm{NE}$ content in the whole spleen following L-deprenyl treatment shows that this increase in NE levels is due to restoration of sympathetic NA nerve fibers in the spleen (data not shown). In earlier studies, L-deprenyl treatment of old and young sympathectomized male F344 rats was able to promote the growth of sympathetic NA nerve fibers in various compartments of the white pulp of the spleen and, thus, the newly established fibers were able to synthesize NE [10-13]. Similar to the pattern of splenic NA innervation of old male F344 rats, the density of innervation in L-deprenyl-treated old female F344 rats was not restored fully to that observed in the white pulp of young rats (data not shown).

Immunosenescence in rodents and humans is due to a lack of age-associated differences in the ability of $\mathrm{T}$ cells to produce Th1 cytokines, IL-2/IFN- $\gamma$ or due to a shift in
T-cell subsets [18-20]. A decline in IL-2 production by splenocytes was not observed in 19- to 21-month-old female rats in the present study but was observed in 24- to 31-month-old female rats [17], which can be attributed to the difference in the age of the female rats selected for this study. L-Deprenyl treatment of old female rats increased IL-2 production and reversed the age-related reduction in IFN- $\gamma$ production in the spleen. Similar immunostimulatory properties of L-deprenyl were reported in the spleens of old male F344 rats and tumor-bearing rats [1, 2, 10-13] and, also, in peripheral blood mononuclear cells of healthy humans in which there was an increased production of proinflammatory cytokines, IL-1 and IL-6 [21]. It is unclear whether these changes in cytokine production are associated with L-deprenyl-induced alterations in the populations of T-helper, T-cytotoxic, and T-regulatory lymphocytes, but the improvement in cytokine production may have been due to the release of NE by the newly established NA nerve fibers in the spleen as it is an important signal molecule for T-cell function in the spleen and lymph nodes [22]. Age-related lymphoproliferative responses in the spleens of female rats were not altered by $\mathrm{L}$-deprenyl treatment indicating that it is unable to reverse the age-associated decline in immunological synapse formation due to impaired cytoskeletal signaling pathways and, also, the expression of the costimulatory molecule CD28 on T cells $[23,24]$. These impaired signaling pathways and downregulated expression of major costimulatory molecules such as CD28 in T cells may have been responsible for similar lack of effect of L-deprenyl treatment on T-cell proliferation in the spleens of young and old male rats and tumor-bearing female rats [2, 11-13].

The regeneration of sympathetic NA innervation in the spleen and enhanced cell-mediated immune responses by L-deprenyl may be due to a reduction in the cellular oxidative stress mediated through the enhancement of antioxidant enzyme activities such as superoxide dismutase, catalase, and glutathione peroxidase [25]. Alternatively, neuroprotective properties of L-deprenyl may have been facilitated by its ability to enhance neurotrophic growth factor biosynthesis that is crucial to the maintenance of sympathetic NA neurons $[15,26]$. We have evidence that L-deprenyl treatment of young female rats increased glutathione peroxidase activity, and tyrosine hydroxylase and nerve growth factor expression in the spleen besides improving the activities of superoxide dismutase and catalase activities in the specific regions of the brain which involves nuclear factor$\kappa \mathrm{B}$ and extracellular signal-regulated kinase $1 / 2$ pathways [unpubl. data]. 
In the present study, the effects of the D-isomer of deprenyl, with its amphetamine-like properties [27], were compared to the neuroprotective and immunostimulatory properties of L-deprenyl. D-Deprenyl treatment of old female rats did not alter the age-related reduction in NE levels and IL-2 production but reduced the age-associated T-cell proliferation further in the spleen that may have been due to its amphetamine- and methamphetamine-like effects $[28,29]$. D-Deprenyl treatment prevented the age-related decline in IFN- $\gamma$ production by splenocytes: nevertheless, cell-mediated immunosuppression was evident in D-deprenyl-treated female rats. These are similar to the results of an earlier study in which treatment of old male rats with the D-isomer of desmethyldeprenyl, a metabolite of deprenyl, had no effect on sympathetic NA innervations, NE levels, and immune responses in the spleen [13].

In summary, we report that treatment of old female F344 rats with L-deprenyl partially restored NE levels due to regeneration of sympathetic NA nerve fibers in the spleen, and enhanced splenic mitogen-induced IL-2 and IFN- $\gamma$ production, and these effects are specific to the Lenantiomer of deprenyl. Further studies are needed to explore the factors responsible for the neurorestorative and immunostimulatory properties of L-deprenyl and its mechanism(s) of action involved in this process including intracellular signaling pathways in lymphoid organs during aging.

\section{Acknowledgments}

We thank John Housel, Don Henderson, and Charles Richardson for their excellent technical assistance. We also thank Dr. Phyllis Whiteley, Roche Bioscience, Palo Alto, Calif., USA, for providing the old rats. This study was supported by NIH grants R37 MH42076 and R01 NS044302.

\section{References}

1 ThyagaRajan S, Priyanka HP, Pundir UP: Aging alters sympathetic noradrenergic innervation and immune reactivity in the lymphoid organs: strategies to reverse neuro-immune senescence. BrainImmune 2012 (http://www.brainimmune.com/index php?option $=$ com_content $\&$ view $=$ article $\&$ id=1598:aging-alters-sympathetic-noradrenergic-innervation-and-immune-reactivity-in-the-lymphoid-organs-strategies-toreverse-neuro-immune-senescence\&catid=73:neuro-immune-dysfunction-incommon-human-diseases\&Itemid=417).

-2 ThyagaRajan S, Felten DL: Modulation of neuroendocrine-immune signaling by Ldeprenyl and L-desmethyldeprenyl in aging and mammary cancer. Mech Ageing Dev 2002;123:1065-1079.

-3 Bellinger DL, Millar BA, Perez S, Carter J, Wood C, ThyagaRajan S, Molinaro C, Lubahn C, Lorton D: Sympathetic modulation of immunity: relevance to disease. Cell Immunol 2008;252:27-56.

-4 Felten SY, Bellinger DL, Collier TJ, Coleman PD, Felten DL: Decreased sympathetic innervation of spleen in aged Fischer 344 rats. Neurobiol Aging 1987;8:159-165.

5 Bellinger DL, Ackerman KD, Felten SY, Felten DL: A longitudinal study of age-related loss of noradrenergic nerves and lymphoid cells in the rat spleen. Exp Neurol 1992;116:295-311.
6 Anderson RM, Weindruch RL: The caloric restriction paradigm: implications for healthy human aging. Am J Hum Biol 2012; 24:101-106

7 Willis LM, Shukitt-Hale B, Joseph JA: Modulation of cognition and behavior in aged animals: role for antioxidant- and essential fatty acid-rich plant foods. Am J Clin Nutr 2009;89:1602S-1606S.

-8 Molano A, Meydani SN: Vitamin E, signalosomes and gene expression in T cells. Mol Aspects Med 2012;33:55-62.

$\checkmark 9$ Holland AM, van den Brink MR: Rejuvenation of the aging T cell compartment. Curr Opin Immunol 2009;21:454-459.

10 ThyagaRajan S, Felten SY, Felten DL: Restoration of sympathetic noradrenergic nerve fibers in the spleen by low doses of L-deprenyl treatment in young sympathectomized and old Fischer 344 rats. J Neuroimmunol 1998;81:144-157.

11 ThyagaRajan S, Madden KS, Kalvass JC, Dimitrova SS, Felten SY, Felten DL: L-Deprenyl-induced increase in IL-2 and NK cell activity accompanies restoration of noradrenergic nerve fibers in the spleens of old F344 rats. J Neuroimmunol 1998;92:9-21.

2 ThyagaRajan S, Madden KS, Stevens SY, Felten DL: Anti-tumor effect of L-deprenyl is associated with enhanced central and peripheral neurotransmission and immune reactivity in rats with carcinogen-induced mammary tumors. J Neuroimmunol 2000; 109:95-104.
13 ThyagaRajan S, Madden KS, Stevens SY, Felten DL: Restoration of splenic noradrenergic nerve fibers and immune reactivity in old F344 rats: a comparison between L-deprenyl and L-desmethyldeprenyl. Int J Immunopharmacol 2000;22:523-536.

14 Caslake R, Macleod A, Ives N, Stowe R, Counsell C: Monoamine oxidase B inhibitors versus other dopaminergic agents in early Parkinson's disease. Cochrane Database Syst Rev 2009;4:CD006661.

$\checkmark 15$ Ebadi M, Brown-Borg H, Ren J, Sharma S, Shavali S, El ReFaey H, Carlson EC: Therapeutic efficacy of selegiline in neurodegenerative disorders and neurological diseases. Curr Drug Targets 2006;7:1513-1529.

16 Magyar K, Szende B, Jenei V, Tábi T, Pálfi M, Szöko E: R-Deprenyl: pharmacological spectrum of its activity. Neurochem Res 2010;35: 1922-1932.

17 ThyagaRajan S, Madden KS, Teruya B, Stevens SY, Felten DL, Bellinger DL: Age-associated alterations in sympathetic noradrenergic innervation of primary and secondary lymphoid organs in female Fischer 344 rats. J Neuroimmunol 2011;233:54-64.

18 Davila DR, Kelley KW: Sex differences in lectin-induced interleukin-2 synthesis in aging rats. Mech Ageing Dev 1988;44:231240.

-19 Simioni PU, Costa EH, Tamashiro WM: Aging reduces the primary humoral response and the in vitro cytokine production in mice. Braz J Med Biol Res 2007;40:1111-1120. 
20 Maue AC, Haynes L: CD4+ T cells and immunosenescence - a mini-review. Gerontology 2009;55:491-495.

-21 Müller T, Kuhn W, Krüger R, Przuntek H: Selegiline as immunostimulant - a novel mechanism of action? J Neural Transm Suppl 1998;52:321-328.

22 Madden KS, Moynihan JA, Brenner GJ, Felten SY, Felten DL, Livnat S: Sympathetic nervous system modulation of the immune system. III. Alterations in T and B cell proliferation and differentiation in vitro following chemical sympathectomy. J Neuroimmunol 1994;49:77-87.

-23 Garcia GG, Miller RA: Age-related defects in the cytoskeleton signaling pathways of CD4 T cells. Ageing Res Rev 2011;10:26-34.
24 Weng NP, Akbar AN, Goronzy J: CD28(-) T cells: their role in the age-associated decline of immune function. Trends Immunol 2009; 30:306-312.

25 Kitani K, Minami C, Isobe K, Maehara K, Kanai S, Ivy GO, Carrillo MC: Why (-)deprenyl prolongs survivals of experimental animals: increase of anti-oxidant enzymes in brain and other body tissues as well as mobilization of various humoral factors may lead to systemic anti-aging effects. Mech Ageing Dev 2002;123:1087-1100.

26 Semkova I, Wolz P, Schilling M, Krieglstein J: Selegiline enhances NGF synthesis and protects central nervous system neurons from excitotoxic and ischemic damage. Eur J Pharmacol 1996;315:19-30.
7 Yasar S, Gaál J, Panlilio LV, Justinova Z, Molnár SV, Redhi GH, Schindler CW: A comparison of drug-seeking behavior maintained by D-amphetamine, L-deprenyl (selegiline), and D-deprenyl under a second-order schedule in squirrel monkeys. Psychopharmacology (Berl) 2006;183:413-421.

28 Freire-Garabal M, Balboa JL, Núñez MJ, Castaño MT, Llovo JB, Fernández-Rial JC, Belmonte A: Effects of amphetamine on Tcell immune response in mice. Life Sci 1991; 49:PL107-PL112.

29 Yu Q, Zhang D, Walston M, Zhang J, Liu Y, Watson RR: Chronic methamphetamine exposure alters immune function in normal and retrovirus-infected mice. Int Immunopharmacol 2002;2:951-962. 